associated in multivariate analysis with the following baseline factors: diagnosis of SpA (OR 9.65 [3.21 - 28.96]; $p=0.039^{*}$ ), total sacro iliac MRI inflammatory SPARCC score (central reading) over median (OR 3.98 [2.26 - 7]; $p=0.015^{*}$ ), dactylitis (OR 4.7 [2.65 -8.36$]$; $p=0.007^{\star *}$ ), syndesmophyte score over median (central reading) (OR $0.22[0.1-0.45] ; \mathrm{p}=0.039^{\star}$ ).

No significant association was found with HLA-B27, cs or b DMARDs, BASDAI, ASDAS, BASFI.

Conclusion: Five-years data of the DESIR cohort allowed an estimation of incidence rate of uveitis of 1.3/100p-y; over five years, uveitis was associated with dactylitis, biologic and sacro iliac MRI inflammation.

References:

[1] Wendling D, et al.Arthritis Care Res(Hoboken). 2012 Jul;64(7):1089-93. Disclosure of Interests: Daniel Wendling: None declared, Clément Prati: None declared, Thierry Lequerre: None declared, Corinne Miceli Richard: None declared, Maxime Dougados Grant/research support from: AbbVie, Eli Lilly, Merck, Novartis, Pfizer and UCB Pharma, Consultant of: AbbVie, Eli Lilly, Merck, Novartis, Pfizer and UCB Pharma, Speakers bureau: AbbVie, Eli Lilly, Merck, Novartis, Pfizer and UCB Pharma, Anna Moltó Grant/research support from: Pfizer, UCB, Consultant of: Abbvie, BMS, MSD, Novartis, Pfizer, UCB, xavier guillot: None declared

DOI: 10.1136/annrheumdis-2020-eular.1554

\section{FRI0326 PREVALENCE AND IMPACT OF COMORBIDITIES IN AXIAL SPONDYLOARTHRITIS: SYSTEMATIC REVIEW AND META-ANALYSIS}

S. S. Zhao ${ }^{1,2}$, S. Robertson ${ }^{1}$, T. Reich ${ }^{1}$, N. L. Harrison ${ }^{2}$, R. J. Moots ${ }^{1,2}$,

N. Goodson ${ }^{1,2} .{ }^{1}$ University of Liverpool, Liverpool, United Kingdom; ${ }^{2}$ Aintree University Hospital, Liverpool, United Kingdom

Background: Comorbidities are common among patients with axial spondyloarthritis (axSpA). The majority of axSpA patients have at least one comorbid medical condition in addition to any extra-articular manifestations [1]. Comorbidity 'burden' is associate with poorer function, quality of life and work-related outcomes [2]. They also influence treatment decisions and are key drivers of mortality.

Objectives: We performed a systematic review and meta-analysis to 1) describe the prevalence of commonly reported comorbidities, 2) compare the prevalence of comorbidities between axSpA and control populations.

Methods: A systematic review was performed in September 2019 using Medline, PubMed, Scopus and Web of Science, in accordance with PRISMA guidelines. Studies were included if they reported the prevalence of comorbidities on disease outcomes, and excluded if they focused on a single comorbidity or closely related diseases in one organ system. Two independent reviewers screened titles and abstracts, assessed full-texts for eligibility and extracted data from qualifying studies. Where possible, we performed meta-analyses for comorbidities reported by at least 3 studies using random-effects models. Pooled prevalence estimates were reported as percentages (95\% confidence interval, $\mathrm{I}^{2}$ statistic for heterogeneity).

Results: 36 studies reported prevalence of of individual comorbidities, amounting to a combined sample size of 119,427 patients. The most prevalent individual comorbidities were hypertension (pooled prevalence $22 \%$ ), hyperlipidaemia $(17 \%)$ and obesity (14\%) (Figure 1). Eleven studies consistently showed higher prevalence of comorbidities in axSpA than controls (Table 1); odds ratios (OR) were particularly large for depression (pooled OR 1.80) and congestive cardiac failure (OR 1.84). There was significant heterogeneity for the majority of meta-analysis estimates.

Table 1. Meta-analysis estimates for odds ratios (OR) of comorbidities compared between axSpA and control groups.

\begin{tabular}{lcccc}
\hline & Number of studies & Pooled OR & 95\% confidence interval & I $^{2}$, \% \\
\hline Hypertension & 9 & 1.58 & 1.29 to 1.92 & 98 \\
Any cardiovascular disease & 3 & 1.42 & 0.999 to 2.03 & 99 \\
Any ischaemic heart disease & 7 & 1.51 & 1.21 to 1.87 & 87 \\
Congestive cardiac failure & 4 & 1.84 & 1.25 to 2.73 & 89 \\
Stroke & 6 & 1.30 & 1.04 to 1.62 & 81 \\
Peripheral vascular disease & 5 & 1.47 & 1.10 to 1.96 & 83 \\
Diabetes & 8 & 1.14 & 1.001 to 1.30 & 83 \\
Hyperlipidaemia & 5 & 1.18 & 1.01 to 1.39 & 94 \\
Cancer & 5 & 1.22 & 1.01 to 1.47 & 93 \\
Depression & 4 & 1.80 & 1.45 to 2.23 & 92 \\
\end{tabular}

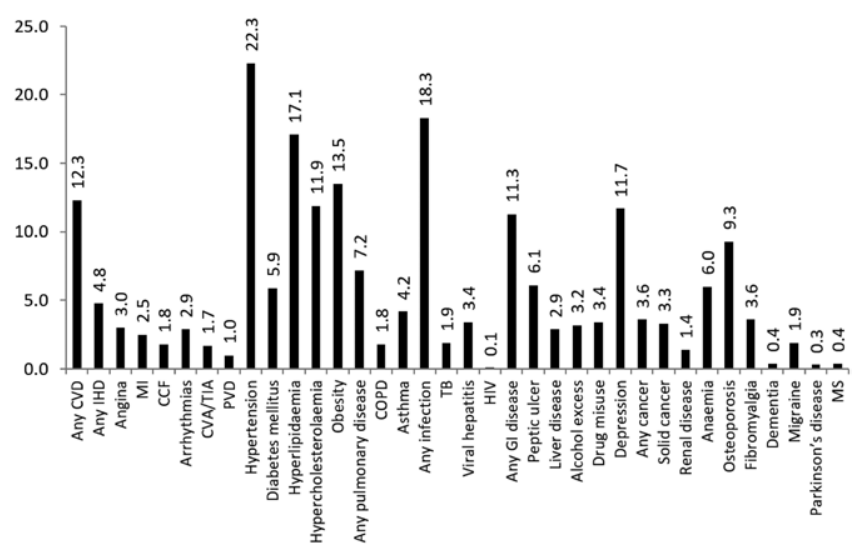

Figure 1. Pooled prevalence of individual comorbidities.

Conclusion: Comorbidities are common in axSpA. Almost all comorbidities examined were more prevalent in axSpA patients than age and sex matched controls, with $\geq 80 \%$ higher odds for congestive cardiac failure and depression. Systematic and repeated assessments should therefore be integrated into routine clinical practice to ensure holistic patient-centred management. Additional studies are needed to validate comorbidities indices for axSpA research. References:

[1] Zhao SS, Radner H, Siebert S, et al. Comorbidity burden in axial spondyloarthritis: a cluster analysis. Rheumatology. 2019 Oct 1;58(10):1746-54.

[2] Nikiphorou E, Ramiro S, van der Heijde D, et al. Association of Comorbidities in Spondyloarthritis With Poor Function, Work Disability, and Quality of Life: Results From the Assessment of SpondyloArthritis International Society Comorbidities in Spondyloarthritis Study. Arthritis Care Res. 2018 Aug;70(8):1257-62.

Disclosure of Interests: None declared

DOI: 10.1136/annrheumdis-2020-eular.1252

\section{FRI0327 QUALITY OF LIFE, QUALITY OF SLEEP AND PRESENCE OF RESTLESS LEG SYNDROME IN ANKYLOSING SPONDYLITIS}

S. Zontul ${ }^{1}$, A. K. Cengiz ${ }^{2}$, Z. Altay ${ }^{3} .{ }^{1}$ Ministry of Health Batman District Hospital, Rheumatology, Batman, Turkey; ${ }^{2} 19$ Mayis University Faculty of Medicine, Physical Medicine and Rehabilitation-Rheumatology, Samsun, Turkey; ${ }^{3}$ Inonu University Faculty of Medicine, Physical Medicine and Rehabilitation, Malatya, Turkey

Background: For chronic diseases like ankylosing spondylitis (AS), improving patients quality of life (QOL) is one of the main aims of the therapy. Sleep quality is an important determinant of QOL. Restless leg syndrome (RLS) is a frequent disorder that disturbs patients QOL.

Objectives: The aim of this study is to evaluate the sleep quality of patients with AS and to determine the possible reasons of sleep disorder like pain, disease activity, functional status, depression, anxiety, presence of RLS and their impact on patients QOL.

Methods: One hundred twenty two patients with ankylosing spondylitis were enrolled in the study. Quality of life was evaluated by using short form-36 (SF36). Beck depression and Beck anxiety indices were used to evaluate the mood of the patients. Sleep quality was determined with Pittsburg Sleep Quality Index. International Restless Leg Study Group (IRLSSG) criteria was used to determine the co-existing restless leg syndrome. Demographic data including age, sex, height, weight, marital status, educational status, disease duration and medical treatments were noted. BASDAI (Bath ankylosing spondylitis disease activity index),BASMI (Bath ankylosing spondylitis metrology index) and BASFI (Bath ankylosing spondylitis functional index) are determined and perceived pain level was evaluated by visual analog scale for pain (VASpain) for all patients.

Results: According to Pittsburg Sleep Quality Index 48 patients (39.3\%) had bad sleep quality. When patients with bad sleep quality were compared with the patients with good sleep quality according to SF-36, BASDAI, BASMI,BASFI, VAS pain, Beck depression and Beck anxiety indices worse scores were obtained in patients with bad sleep quality. The difference between two groups were statistically significant for almost all of the listed parametres (Table-1). Restless leg syndrome (RLS) was determined in $36.06 \%$ (44/122) of AS patients. RLS was more common in patients with bad sleep quality but the difference did not reach statistical significance. 
Conclusion: Sleep disorders are common in patients with AS and these disorders are found to be closely associated with pain, disease activity, anxiety, depression and poor quality of life. Restless leg syndrome (RLS) is also common in patients with AS and it is not always associated with bad sleep quality. RLS was determined in $32.4 \%$ (24/74) of patients whose sleep quality is good according to the Pittsburg Sleep Quality Index. So to improve the quality of life in AS, presence of RLS must be evaluated along with the sleep quality.

References:

[1] Tekatas A,. Pamuk ON. Increased frequency of restless leg syndrome in patients with ankylosing spondylitis. International Journal of Rheumatic Diseases, 2015, 18, 58-62.

Table 1.

\begin{tabular}{lccr}
\hline $\begin{array}{l}\text { Parametres } \\
\text { median (min-max) }\end{array}$ & Good sleep Quality & Bad sleep quality & $\mathrm{P}$ \\
\hline SF36 physical functioning & & & \\
SF36 Social functioning & $85(20-100)$ & $65(25-100)$ & $\mathbf{0 , 0 0 0 1}$ \\
SF36 Role physical & $100(0-100)$ & $62,5(12,5-100)$ & $\mathbf{0 , 0 0 0 1}$ \\
SF36 Role emotional & $100(0-100)$ & $0(0-100)$ & $\mathbf{0 , 0 0 0 1}$ \\
SF36 Mental health & $74(20-100)$ & $33,3(0-100)$ & $\mathbf{0 , 0 0 3}$ \\
SF36 Vitality & $55(10-90)$ & $52(12-88)$ & $\mathbf{0 , 0 0 0 1}$ \\
SF36 Bodily pain & $88,8(11,1-100)$ & $30(0-80)$ & $\mathbf{0 , 0 0 0 1}$ \\
SF36 General health & $50(15-100)$ & $44,4(0-100)$ & $\mathbf{0 , 0 0 0 1}$ \\
Beck depression & $5(0-28)$ & $35(0-95)$ & $\mathbf{0 , 0 0 0 1}$ \\
Beck anxiety & $5.5(0-45)$ & $14.5(1-44)$ & 0.0001 \\
BASDAl & $1.6(0-5.91)$ & $3.5(1-49)$ & $\mathbf{0 . 0 0 0 1}$ \\
BASFI & $1.2(0-8.1)$ & $2.85(0.8-8-7.3)$ & $\mathbf{0 . 0 0 0 1}$ \\
BASMI & $1(0-9)$ & $1.5(0-8)$ & $\mathbf{0 . 0 0 0 1}$ \\
VAS pain & $1(0-8)$ & $5(0-10)$ & 0,087 \\
Restless Leg Syndrome (\%) & $32.4 \%(24 / 74)$ & $41.7 \%(20 / 48)$ & $\mathbf{0 . 0 0 0 1}$ \\
& & & 0.299 \\
\hline
\end{tabular}

Disclosure of Interests: None declared

DOI: 10.1136/annrheumdis-2020-eular.3096

\section{FRIDAY, 05 JUNE 2020}

\section{Psoriatic arthritis}

\section{FRI0328 $\quad$ PROFILING OF THE IMMUNE COMPARTMENT IN THE TISSUE ENVIRONMENT OF PSORIATIC ARTHRITIS USING RNASEQ}

G. Ang ${ }^{1}$, P. Kumar ${ }^{1}$, D. Guo ${ }^{1}$, A. Lajam ${ }^{1}$, W. Fong ${ }^{2}$, Y. Y. Leung ${ }^{2}$, S. Albani ${ }^{1}$

${ }^{1}$ Translational Immunology Institute, Singapore, Singapore; ${ }^{2}$ Singapore General Hospital, Singapore, Singapore

Background: Psoriasis is a chronic inflammatory disease of the skin with a reported prevalence of $0.09-11.4 \%$ of the population (1). 1 in 4 psoriasis patients also have psoriatic arthritis (PSA) (2), with additional joint involvement that can be associated with significant morbidity. Despite its relative commonness, the aetiology of psoriasis is not well understood, and there is no cure for this disease. Additionally, up to $30 \%$ of PsA patients with active disease are recalcitrant to treatment. Thus it remains a prerogative to understand the immune mechanisms contributing to the development of the disease in order to inform strategies for novel therapies.

Objectives: Our aim was to identify perturbations in local tissue immune networks that could contribute to the pathology of psoriasis and psoriatic arthritis. We hypothesise that psoriasis is driven by a disrupted tissue microenvironment, which then provides cues to a susceptible peripheral immune system to drive pathology. Thus as the first part of our study, we investigated the transcriptional profiles of normal and lesional skin.

Methods: Skin punch biopsies were obtained from both lesional and morphologically normal skin of 4 PsA patients with active disease. CD45+ cells were isolated using magnetic enrichment for RNA purification and subsequent RNAseq. Differently expressed genes (DEG) were identified and pathway analysis performed using the integrated Differential Expression and Pathway (iDEP) analysis tool. Gene set enrichment analysis was performed using GSEA.

Results: Transcriptomic analyses of skin revealed that lesional skin, compared to non-lesional sites, was enhanced for expression of genes associated with immune processes (including genes such as such as IL17A, FCN1, and CTLA4) anti-microbial responses (such as DEF4BA and S100A8) and immune cell chemotaxis (notably CXCL13 and SELPLG), suggesting a possible inflammatory response to skin microbiota. Interestingly, lesional skin showed a deficiency in expression of genes associated with tRNA metabolic processes (including $A A R S, Y A R S$, and other aminoacyl tRNA synthetases), suggesting a possible defect in protein translation. Similarly, pathway analysis revealed an enrichment in humoral immune response pathways in PsA lesional skin, and a comparative deficiency in RNA metabolic pathways.

Conclusion: Our transcriptional approach provides a comprehensive overview of localised immunity in psoriasis and predicts intimate interactions with the peripheral immune system. Further studies are ongoing to uncover cell types involved, as well as parallels at other disease sites (joints). These findings will facilitate the identification of novel targets for treatment of PsA.

References:

[1] World Health Organization (2016). Global report on psoriasis. [Online] (https:// apps.who.int/iris/bitstream/handle/10665/204417/9789241565189 eng pdf.psoriasis; jsessionid=54912784D28C9F36ECCD45471AC5775B?sequence $=1$, accessed 24 January 2020)

[2] Alinaghi F., Calov M., Kristensen L.E., Gladman D.D, Coates L.C., Julien D., Gottlieb A.B., Gisondi P., Wu J.J., Thyssen J.P., Egeberg A. (2019) Prevalence of psoriatic arthritis in patients with psoriasis: A systemic review and meta-analysis of observational and clinical studies. Journal of the American Academy of Dermatology., 80(1), 251-265.

Disclosure of Interests: Gladys Ang: None declared, Pavanish Kumar: None declared, Dianyan Guo: None declared, Ahmad Lajam: None declared, Warren Fong Consultant of: Abbvie, Janssen, Novartis, Speakers bureau: Abbvie, Janssen, Novartis, Ying Ying Leung Speakers bureau: Novartis, Janssen, Eli Lilly, Salvatore Albani: None declared

DOI: 10.1136/annrheumdis-2020-eular.2108

\section{FRI0329 \\ ASSOCIATION BETWEEN PERITENON EXTENSOR TENDON INFLAMMATION AND ENTHESITIS IN TUNISIAN PATIENTS WITH PSORIATIC ARTHRITIS}

K. Ben Abdelghani ${ }^{1}$, H. Boussaa ${ }^{1}$, S. Miladi ${ }^{1}$, A. Fazaa ${ }^{1}$, K. Ouenniche ${ }^{1}$, L. Souabni ${ }^{1}$, S. Kassab ${ }^{1}$, S. Chekili ${ }^{1}$, A. Laatar ${ }^{1} .{ }^{1}$ Mongi Slim Hospital, Rheumatology, Tunis, Tunisia

Background: Ultrasonography (US) is a useful tool in assessing psoriatic arthritis (PsA) by detecting synovitis and Power Doppler (PD) activity. Enthesitis is well known as a cornerstone of PsA physiopathology. Recently, more specific US features of PsA have emerged, such as peritenon extensor tendon inflammation (PTI) and edema of soft tissues, with value in the positive diagnosis of the disease.

Objectives: The aim of our study was to determine the association between PTI, edema and enthesitis in PsA patients.

Methods: Patients with peripheral PsA responding to the Classification Criteria for Psoriatic Arthritis (CASPAR) were included. US examination was performed by an experimented rheumatologist blinded to clinical data using a machine type Esaote MyLAb 60 with a linear probe of $6-18 \mathrm{MHz}$. Wrists, metacarpo-phalangeal (MCP), proximal inter-phalangeal (PIP) and distal inter-phalangeal (DIP) joints were assessed in mode B and PD. PTI was defined as a hypoechoic image surrounding the digitorum tendon with or without PD signal in the dorsal aspect of MCP joints. Soft tissue edema was defined as a diffuse enlargement of soft tissue around the flexor tendon, with an increased PD signal, from finger pad to MCP joint and was evaluated by volar scan. Enthesitis of the digitorum extensor tendon at the dorsal aspect of DIP joint and synovitis were defined according to the OMERACT definitions.

A $p<0.05$ was considered statistically significant.

Results: A total of 600 joints were assessed in 20 PsA patients, 8 men and 12 women, with a mean age of $55 \pm 11$ [33-77] years old. The mean disease duration was of $10 \pm 8$ [1-34] years. Clinically, $25 \%$ of joints were tender and $6 \%$ were swollen. The mean DAPSA (Disease Activity in PSoriatic Arthritis) score was of $32 \pm 27$ [4-112].

On US examination, synovitis was detected in 54 joints (9\%), with PD signal in $53 \%$ of them. The sites of synovitis by decreasing order of frequency were: MCP in $38 \%$, wrists in $26 \%$, PIP in $19 \%$ and PID in $13 \%$ of cases.

PTI was noted in $24 \mathrm{MCP}$ joints (12\%) with PD signal in one case, and soft tissue edema in $6 \mathrm{MCP}$ joints (3\%).

Enthesitis was noted in 59 DIP joints (37\%). The elementary lesions recorded were: enthesophytes in $64 \%$, erosions in $20 \%$, calcifications in $13 \%$ and thickened and/or hypoechoic tendon in $12 \%$ of cases. However, no PD signal at the enthesis was found.

PTI and soft tissue edema had no association with enthesitis $(p=0.399$ and $\mathrm{p}=0.374$ respectively). PD synovitis showed a significant association with enthesitis $(p=0.034)$, but not with PTI and soft tissue edema. GS synovitis had no association with any of these lesions.

Conclusion: Our study found PTI and soft tissue edema not to be associated with enthesitis as opposed to PD synovitis. A larger sample size is necessary to support the role of $\mathrm{PTI}$ as an enthesis related lesion in PsA patients.

Disclosure of Interests: None declared

DOI: 10.1136/annrheumdis-2020-eular.3931 